\title{
Phone Interviews for Preoperative Medical Evaluation for Cataract Surgery
}

\author{
Manju L. Subramanian, $M D^{7}$, Avni Badami, $M D^{2}$, Frank Vavrek II, BS ${ }^{2}$, \\ Pamela Rosenkranz, RN, BSN, Med ${ }^{3}$, and Susannah Rowe, MD, MPH ${ }^{1,2}$ \\ 'Department of Ophthalmology, Boston University School of Medicine, Boston, MA, USA; ${ }^{2}$ Boston Medical Center, Boston, MA, USA; ${ }^{3}$ Clinical \\ Quality and Patient Safety at Boston Medical Center, Boston University School of Medicine, Boston, MA, USA.
}

KEY WORDS: preoperative evaluation; ophthalmology; access to care; primary care.

J Gen Intern Med 34(7):1121-2

DOI: $10.1007 / \mathrm{s} 11606-019-04840-y$

(c) Society of General Internal Medicine 2019

\section{INTRODUCTION}

Cataract surgery is the most commonly performed procedure among developed nations. As the prevalence of eye surgery increases with advancing age, so do resources on preoperative medical assessments. Increasing attention has been devoted to understanding what constitutes appropriate preoperative evaluation for low-risk, minimally invasive eye procedures requiring monitored intravenous (IV) sedation with local anesthesia. The purpose of this study was to retrospectively review an initiative obtaining a history and giving preoperative instructions by phone to determine if it could safely substitute for a standard, in-person history and physical (H\&P) in patients undergoing cataract surgery at Boston Medical Center (BMC).

\section{METHODS}

Joint Commission was consulted, who gave BMC flexibility in defining a preoperative history and physical, and a phone visit initiative was subsequently implemented in October 2015 for all patients undergoing cataract surgery. Surgeons were allowed to request a standard H\&P if deemed necessary, but this occurred rarely. If concerns were identified during the phone visit (such as the inability to lie flat on a bed), patients were asked to come in for a standard H\&P. With IRB approval, these cases were retrospectively reviewed. Measured outcomes were postoperative mortality, unplanned admissions, compliance rate with phone visits, and same day surgery cancellations.

Prior Presentation Phone Interviews for Preoperative Medical Evaluation for Cataract Surgery, Poster presentation, Association for Research in Vision and Ophthalmology, 2018.

Published online February 7, 2019

\section{RESULTS}

This study included 4966 subjects scheduled to undergo cataract surgery. During the 3-year study period (October 1, 2014, to September 30, 2017, 1 year prior and 2 years after initiation of phone visits), 2055 patients underwent phone visits and 2911 patients underwent standard H\&Ps (Table 1). There were no unplanned admissions and no mortalities within 30 days following surgery for all 4966 patients. Noncompliance rates for phone visits $(13 \%)$ were significantly lower compared to standard H\&Ps (21\%), $p \leq$ 0.0001 . Same day surgery cancellations were significantly lower 2 years after initiation of the pilot (Table 2). The phone interviews took $15 \mathrm{~min}$ compared to $45 \mathrm{~min}$ for a standard H\&P, freeing up $27 \mathrm{~h} /$ week and allowing medical clearance of three times as many patients.

\section{DISCUSSION}

Routine preoperative medical testing is no longer the standard practice for patients undergoing cataract surgery (the cost associated is $2.55 \times$ higher compared to selective medical testing). ${ }^{1,2}$ However, history and physicals are required by the Centers for Medicare and Medicaid Services for all patients within 30 days of surgery. This case series found that phone visits in lieu of standard H\&Ps in patients scheduled for cataract surgery were not associated with increased unplanned admissions, mortality, or surgery cancellations. It helped streamline appointments and allowed providers to focus on more complex patients undergoing surgery with general anesthesia. Noncompliance with preoperative assessments and same day surgery cancellations were significantly lower for phone visits. The reason for reduced cancellations is unclear, but it may be due to an increased presence of comorbidities in those undergoing standard H\&Ps, leading to higher number of cancellations for medical reasons.

Publication by Schein et al. argues that cataract surgery is "remarkably safe" and there is no evidence that a required history and physical adds benefit beyond the screening performed on the day of surgery by the surgeon and anesthesiologist. ${ }^{3}$ Jastrzebski et al. also advocates a 
Table 1 Total Patients Scheduled in Preoperative Assessment Clinic

\begin{tabular}{lll}
\hline \hline Year & Standard H\&Ps & Phone interviews \\
\hline FY2015 (prior to initiation of phone visits) & 1647 & 2 \\
FY2016 & 557 & 1088 \\
FY2017 & 707 & 965 \\
Total & 2911 & 2055 \\
\hline
\end{tabular}

Volume discrepancy in Tables 1 and 2 is due to duplicate entries of those who did not show for both standard and phone H\&P visits and were rescheduled

Table 2 Same Day Cancellations for Surgery

\begin{tabular}{llll}
\hline \hline & $\begin{array}{l}\text { FY2015 (Oct 2014-Sept 2015) } \\
\text { prior to initiation of phone interviews }\end{array}$ & $\begin{array}{l}\text { FY2016 } \\
\text { (Oct 2015-Sept 2016) }\end{array}$ & $\begin{array}{l}\text { FY2017 } \\
\text { (Oct 2016-Sept 2017) }\end{array}$ \\
\hline$n$ & 2096 & 1931 & 1613 \\
Cancellations & $101(4.8 \% ; 95 \%$ CI 3.98-5.82\%) & $75(3.9 \% ; 95 \%$ CI $3.11-4.84 \%)$ & $49(3.0 \% ; 95 \%$ CI $2.30-4.00 \%)$ \\
Odds ratio & 1 & $0.80,95 \%$ CI $0.59-1.08, p=0.148$ & $0.62 ; 95 \%$ CI $0.44-0.88, p=0.007$ \\
\hline
\end{tabular}

graded approach to preoperative assessments. ${ }^{4}$ Based on our results, we believe the universal application of independent and complete in-person H\&Ps for patients undergoing cataract surgery is not medically necessary for most patients, represents low-value care, and increases visit burden. At BMC phone visits are now standard for all eye surgery, including non-cataract eye procedures, and is considering expansion of phone visits to other non-ocular procedures that are similarly short in duration requiring monitored IV sedation.

Acknowledgements: Contributors: Ryan Macht, MD, Gheorghe Doros, $P h D$, and Jeffrey J. Siracuse, $M D$

Corresponding Author: Manju L. Subramanian, MD; Department of Ophthalmology Boston University School of Medicine, 85 East Concord Street, no. 8813, Boston, MA 02118, USA (e-mail: Manju. subramanian@bmc.org).

\section{Compliance with Ethical Standards:}

Conflict of Interest: The authors declare that they do not have a conflict of interest.

Publisher's Note Springer Nature remains neutral with regard to jurisdictional claims in published maps and institutional affiliations.

\section{REFERENCES}

1. Schein OD, Katz J, Bass EB, et al. The value of routine preoperative medical testing before cataract surgery: study of medical testing for cataract surgery. N Engl J Med 2000;342:168-75.

2. Lira RP, Nascimento MA, MoreiraFilho DC et al. Are routine preoperative medical tests needed with cataract surgery? Rev Panam Salud Publica 2001;10:13-7.

3. Schein OD, Pronovost PJ. A preoperative medical history and physical should not be a requirement for all cataract patients. J Gen Intern Med. 2017;32(7):813-814.

4. Jastrzebski A, Villafranca A, Sethi S, Bellan L, Misericordia Health Centre Cataract Surgery Working Group. Safety and comparative costs of preoperative assessments for cataract surgery: traditional mandatory assessment versus a novel graded system. Can J Anaesth. 2016;63(7):842-50. 